\title{
Tailor-Made Amphiphilic Biodegradable Polymer-Gels: 1. Gel Preparation via Controlled Ring-opening Polymerization Using Glucopyranoside As Initiator and Subsequent Coupling with $\alpha, \omega$-Bifunctional PEG
}

\author{
By Yutaka MorIKaWA,${ }^{1}$ Hiromi KINOSHITA, ${ }^{1}$ Masumi ASAHI, ${ }^{2}$ Akinori TAKASU,${ }^{1, *}$ and Tadamichi HIRABAYASHI ${ }^{1}$
}

\begin{abstract}
Novel amphiphilic and biodegradable gels composed of glucopyranoside, poly ( $\varepsilon$-caprolactone) (PCL, $\mathrm{n}=25-63$ ), and poly (ethylene glycol) (PEG, $\mathrm{m}=3$ ) were synthesized. Methyl 2,3-di- $O$-benzyl- $\alpha$-D-glucopyranoside was used as an initiator for ring-opening polymerization (ROP) of $\varepsilon$-caprolactone $(\varepsilon-\mathrm{CL})$. The primary hydroxyl group (6-OH) in the above sugar derivative acted chemoselectively as the initiator for living ROP of $\varepsilon$-CL, yielding sugar-headed PCL with various lengths of PCL-chains. The polymerization temperature $\left(60^{\circ} \mathrm{C}\right)$ is very important to suppress the competitive initiation reaction from the secondary hydroxyl group $(\mathrm{C} 4-\mathrm{OH})$. In order to prepare the cross-linker, both $\alpha$ and $\omega$-termini of PEO ( $\mathrm{n}=3$ and 23 ) were converted to dicarboxylic chlorides, which actually acted as a coupling reagent for tailor-made amphiphilic biodegradable gel having a sequence of "Sugar-PCL-PEG-PCL-Sugar."

KEY WORDS: D-Glucose / Poly( $\varepsilon$-caprolactone) (PCL) / Poly(ethylene glycol) (PEG) / Biodegradability / Amphiphilic Gel /
\end{abstract}

Polymers possessing biocompatibility and biodegradability have been investigated extensively in the fields of medicine and agricultural chemicals from environmental viewpoints. In particular, poly( $\varepsilon$-caprolactone) (PCL)-Poly(ethylene oxide) (PEO) block copolymers are interesting for their biodegradability in addition to amphiphilic character, temperaturedependence associated ability, coordination with a particular metallic ion, unique permeable behavior, and so on. ${ }^{1-6}$ The biodegradation rate of PCL-PEO block copolymer can be controlled by the molar balance of both components. ${ }^{7}$

On the other hand, the development of new gelators for a wide range of solvents has recently been sought for a new gel design. Polysaccharides have recently attracted attention for their peculiar capability of interaction with microorganisms. Drug delivery gel systems based on some natural polysaccharides, e.g. dextrin and glucomannan, were investigated. ${ }^{8-10}$ They are biocompatible and biodegradable materials. However, their molecular size and structure are ambiguous. Therefore, it is difficult to control the physical properties of the gels finely. In addition, D-glucose is a typical monosaccharide and an important material for producing biodegradable plastics. Also, D-glucopyranoside has a primary hydroxyl group at the C-6 position and three secondary ones at $\mathrm{C}-2,3$, and 4 carbons. They would contribute to the use of glucopyranoside as a multifunctional chemical reagent. ${ }^{11,12}$ Gross et al. reported an enzyme-catalyzed regioselective ring-opening polymerization (ROP) of caprolactone (chemoselective initiation from C6 hydroxyl group). ${ }^{13}$ Recently, on the synthesis of a hyperbranched hydrogel, glucopyranosides were used as gelators for formation of sugar-containing gels. ${ }^{14,15}$
In this study, we report well-defined gelatinous materials consisting of sugar as a cross-linked point and PCL-PEO block copolymer to control the hydrophilic/lipophilic balance via ring-opening polymerization technique. First, ring-opening polymerization (ROP) of $\varepsilon$-CL using D-glucopyranoside derivative as the initiator is reported in details (Scheme 1). Optimum conditions were surveyed to obtain the well-defined sugar-headed PCL. Subsequently, gelation occurred by coupling reactions between sugar-headed PCL and $\alpha, \omega$-bifunctionalized PEG.

\section{EXPERIMENTAL}

\section{Materials}

Methyl $\alpha$-D-glucopyranoside, triethylene glycol, ethyl $\alpha$ bromoacetate, and tin(II) triflate $\left[\mathrm{Sn}(\mathrm{OTf})_{2}\right]$, tin(II) octanoate $\left[\mathrm{Sn}(\mathrm{Oct})_{2}\right]$ were obtained commercially from Sigma Aldrich Japan Co. Thionyl chloride, benzyl chloride, and $\varepsilon$-caprolactone $(\varepsilon-C L)$ were purchased from Nacalai Tesque Inc. PEG $(\mathrm{m}=3$ and 23). Benzaldehyde dimethylacetal was purchased from Wako Pure Chemical Industries Ltd. Scandium trifluoromethanesulfonate $\left[\mathrm{Sc}(\mathrm{OTf})_{3}\right]$ was purchased from Tokyo Kasei Kogyo Co. Ltd. Methanol, ethyl acetate, tetrahydrofuran (THF), toluene, and hexane were purified by distillation. All other reagents were of the highest available commercial grade.

\section{Synthesis of Sugar-type Initiator}

Methyl 2,3-di- $O$-benzyl- $\alpha$-D-glucopyranoside ${ }^{16-19}$ was synthesized according to Scheme 1 and was used as the initiator for ROP of $\varepsilon$-CL.

\footnotetext{
${ }^{1}$ Graduate School of Engineering, Nagoya Institute of Technology, Gokiso-cho, Showa-ku, Nagoya 466-8555, Japan

${ }^{2}$ Nagoya Municipal Industrial Research Institute, Rokuban-cho, Atsuta-ku, Nagoya 456-0058, Japan

*To whom correspondence should be addressed (Tel: +81-52-735-7159, Fax: +81-52-735-5342, E-mail: takasu.akinori@ nitech.ac.jp).
} 

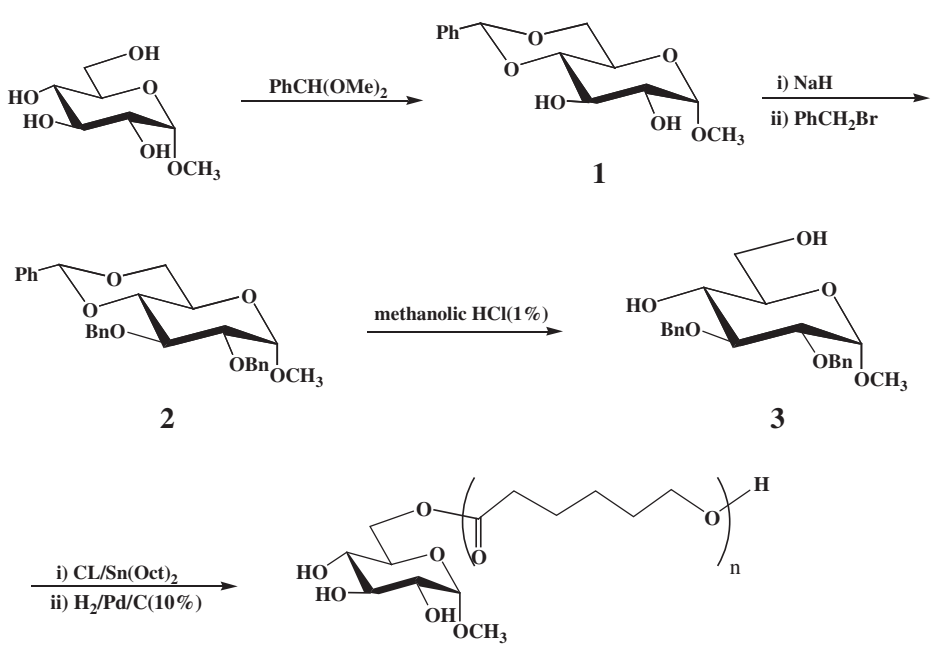

Sugar-Head PCL (n=25-60)

Scheme 1. Synthesis of Sugar-PCL.

Methyl 4,6-di- $\boldsymbol{O}$-Benzylidene- $\boldsymbol{\alpha}$-D-glucopyranoside (1). ${ }^{16}$ Under nitrogen atmosphere, methyl $\alpha$-D-glucopyranoside of $29.2 \mathrm{~g}$ ( $150 \mathrm{mmol}$ ) was dried in vacuo for $1 \mathrm{~h}$ at $60-70^{\circ} \mathrm{C}$ before use, benzaldehyde dimethyl acetal of $22.5 \mathrm{~g}(150 \mathrm{mmol}), \mathrm{Sn}(\mathrm{OTf})_{2}$ $(0.4 \mathrm{~mL}, 1.0 \mathrm{mmol})$, and hot 1,4-dioxan $(200 \mathrm{~mL})$ were placed in a four-neck round flask. The mixture was stirred vigorously, refluxed for $10 \mathrm{~min}$, and cooled again to room temperature. Then $1 \mathrm{~mL}$ of $\mathrm{NH}_{4} \mathrm{OH}$ was added. Evaporation of solvent from the mixture produced a viscous syrup. Methyl 4,6-di- $O$-benzyl$\alpha$-D-glucopyranoside $(42.4 \mathrm{~g}, 90.6 \%)$ was obtained by recrystallization from a 2-propanol/water mixture $(1 / 3, \mathrm{v} / \mathrm{v}) .{ }^{16}$

m.p.: $166-167^{\circ} \mathrm{C}$. IR (KBr disk, $\left.\mathrm{cm}^{-1}\right): 3364\left(v_{\mathrm{O}-\mathrm{H}}\right), 2949$ $\left(v_{\mathrm{C}-\mathrm{H}}\right), 1645$ (aromatic), $1453\left(\delta_{\mathrm{C}-\mathrm{H}}\right), 1075$ and $1029\left(v_{\mathrm{C}-\mathrm{O}}\right)$. ${ }^{1} \mathrm{H}$ NMR $\left(400 \mathrm{MHz}, \mathrm{CDCl}_{3}, \delta, \mathrm{ppm}\right) 7.52-7.47(\mathrm{~m}, 2 \mathrm{H}$, aromatic), 7.40-7.35 (m, 3H, aromatic), $5.56(\mathrm{~s}, 1 \mathrm{H}, \mathrm{PhCH})$, $4.82(\mathrm{~d}, 1 \mathrm{H}, \mathrm{H}-1, J=3.6 \mathrm{~Hz}), 4.31(\mathrm{dm}, 1 \mathrm{H}, \mathrm{H}-6 \mathrm{a}, J=10.0$ $\mathrm{Hz}), 3.94$ (t, 1H, H-4, J = 9.6 Hz), 3.88-3.72 (m, 2H, H-5 and $\mathrm{H}-6 \mathrm{~b}), 3.65$ (dd, $1 \mathrm{H}, \mathrm{H}-2, J=3.6$ and $9.6 \mathrm{~Hz}$ ), 3.49 (t, $1 \mathrm{H}, \mathrm{H}-3$, $J=9.6 \mathrm{~Hz}$ ), 3.47(s, 3H, $\left.\mathrm{OCH}_{3}\right), 2.67$ and 2.24 [2brs, $2 \mathrm{H}, \mathrm{OH}$ (C-3 and 2)].

Methyl 4,6-di- $O$-Benzylidene-2,3-di- $O$-benzyl- $\alpha$-D-glucopyranoside (2). First, 4,6-di- $O$-benzylidene- $\alpha$-D-glucopyranoside $(6.6 \mathrm{~g}, 23.7 \mathrm{mmol})$ and $\mathrm{NaH}(2.3 \mathrm{~g}, 95.0 \mathrm{mmol})$ were stirred in a flask with $250 \mathrm{~mL}$ of DMF for $1 \mathrm{~h}$. Then a benzyl chloride $(10.9 \mathrm{~mL}, 95.0 \mathrm{mmol})$ solution in DMF was added dropwise and stirred for $72 \mathrm{~h}$ at room temperature. The mixture described above was washed with aqueous $\mathrm{NaHCO}_{3}$ and then distilled water. Organic products were extracted using ethyl acetate. After evaporation of ethyl acetate, $6.8 \mathrm{~g}$ of methyl 2,3-di- $O$ benzyl-4,6- $O$-benzylidene- $\alpha$-D-glucopyranoside was obtained $(65.4 \%)$ and purified by recrystallization from methanol. ${ }^{17}$ IR (KBr disk): $2942\left(v_{\mathrm{C}-\mathrm{H}}\right), 1470$ and $1452\left(\delta_{\mathrm{C}-\mathrm{H}}\right), 1087$ and 1029 $\left(v_{\mathrm{C}-\mathrm{O}}\right) .{ }^{1} \mathrm{H} \mathrm{NMR}\left(400 \mathrm{MHz}, \mathrm{CDCl}_{3}, \delta, \mathrm{ppm}\right) 7.52-7.27(\mathrm{~m}$, $15 \mathrm{H}, 3 \times \mathrm{Ph}), 5.55(\mathrm{~s}, 1 \mathrm{H}, \mathrm{PhCH}), 4.91$ and 4.83 (AB-quartet, $2 \mathrm{H}, \mathrm{PhCH}_{2}, J=11.6 \mathrm{~Hz}$ ), 4.86 and 4.70 (AB-quartet, $2 \mathrm{H}$, $\left.\mathrm{PhCH}_{2}, J=12.1 \mathrm{~Hz}\right), 4.59$ (d, 1H, H-1, 3.6 Hz), 4.27 (dd, 1H,
$\mathrm{H}-2, J=3.6$ and $10.0 \mathrm{~Hz}), 4.05(\mathrm{t}, 1 \mathrm{H}, \mathrm{H}-4, J=10.0 \mathrm{~Hz}), 3.82$ $(\mathrm{dt}, 1 \mathrm{H}, \mathrm{H}-5, J=7.8$ and $10.0 \mathrm{~Hz}), 3.70(\mathrm{t}, 1 \mathrm{H}, \mathrm{H}-3, J=$ $10.0 \mathrm{~Hz}), 3.63-3.54$ (m, 2H, H-6a and 6b), 3.40 (s, 3H, $\left.\mathrm{OCH}_{3}\right)$. Methyl 2,3-di- $\boldsymbol{O}$-Benzyl- $\boldsymbol{\alpha}$-D-glucopyranoside (3). Methyl 4,6-di- $O$-benzylidene-2,3-di- $O$-benzyl- $\alpha$-D-glucopyranoside (2) $(2.0 \mathrm{~g}, 4.3 \mathrm{mmol})$ and $26.5 \mathrm{~mL}$ of acidic methanol $(1 \mathrm{vol} \%$ $\mathrm{HCl}$ ) were stirred vigorously at room temperature for $1 \mathrm{~h}$, and saturated $\mathrm{NaHCO}_{3}$ aq. was added for neutralizing $\mathrm{HCl}$. The mixture was extracted with methylene chloride. The organic layer was washed with saturated $\mathrm{NaCl}$ aq. and distilled water. Recrystallization from minimal volume of ethyl acetate with hexanes yield $20.0 \mathrm{~g}(81.2 \%)$ of methyl 2,3-di- $O$-benzyl- $\alpha$-Dglucopyranoside. ${ }^{19}$ m.p.: $72-74{ }^{\circ} \mathrm{C}$. IR (KBr disk): $3429\left(v_{\mathrm{O}-\mathrm{H}}\right)$, $2928\left(v_{\mathrm{C}-\mathrm{H}}\right), 1454\left(\delta_{\mathrm{C}-\mathrm{H}}\right), 1053$, and $1028\left(v_{\mathrm{C}-\mathrm{O}}\right) .{ }^{1} \mathrm{H}$ NMR (400 MHz, $\left.\mathrm{CDCl}_{3}, \delta, \mathrm{ppm}\right): 7.37-7.29(\mathrm{~m}, 10 \mathrm{H}, 2 \times \mathrm{Ph}), 4.99$ and $4.75\left(\mathrm{AB}\right.$-quartet, $\left.2 \mathrm{H}, \mathrm{PhCH}_{2}, J=11.2 \mathrm{~Hz}\right), 4.78$ and 4.67 (AB-quartet, 2H, $\left.\mathrm{PhCH}_{2}, J=12.0 \mathrm{~Hz}\right), 4.59(\mathrm{~d}, 1 \mathrm{H}, \mathrm{H}-1$, $J=3.6 \mathrm{~Hz}), 3.80$ and $3.76(\mathrm{dd}, 2 \mathrm{H}, \mathrm{H}-6 \mathrm{a}$ and $6 \mathrm{~b}, J=7.0$ and $10.1 \mathrm{~Hz}), 3.74$ (m, 1H, H-4), 3.61 (m, 1H, H-5), 3.52 (t, 1H, $\mathrm{H}-3, J=9.8 \mathrm{~Hz}$ ), 3.49 (dd, $1 \mathrm{H}, \mathrm{H}-2, J=3.6$ and $9.8 \mathrm{~Hz}$ ), 3.38 (s, $\left.3 \mathrm{H}, \mathrm{OCH}_{3}\right), 2.44$ [2brs, $2 \mathrm{H}, \mathrm{OH}(\mathrm{C}-4$ and 6$)$ ].

\section{Ring-opening Polymerization of $\boldsymbol{\varepsilon}$-CL}

Toluene and $\varepsilon$-CL were placed in a Schlenk-type reactor with a magnetic bar, and $\mathrm{Sn}(\mathrm{Oct})_{2}$ in toluene was added using a syringe. The reactor was connected with a vacuum line, degassed, and sealed out. After polymerization for a prescribed time at $60^{\circ} \mathrm{C}$, a small amount of methanol was added to stop the polymerization. Crude polymers were precipitated by pouring the mixture into a large amount of $n$-hexane and purified by reprecipitation from a THF solution into $n$-hexane. ${ }^{1} \mathrm{H} \mathrm{NMR}\left(200 \mathrm{MHz}, \mathrm{CDCl}_{3}, \delta, \mathrm{ppm}\right): 7.37-7.29(\mathrm{~m}, 10 \mathrm{H}$, $2 \times \mathrm{Ph}) ; 4.87$ and 4.64 (AB-quartet, $2 \mathrm{H}, \mathrm{PhCH}_{2}, J=11.6 \mathrm{~Hz}$ ), 4.80 and 4.62 (AB-quartet, $\left.2 \mathrm{H}, \mathrm{PhCH}_{2}, J=12.0 \mathrm{~Hz}\right), 4.60(\mathrm{~d}$, $1 \mathrm{H}, \mathrm{H}-1, J=3.6 \mathrm{~Hz}), 4.40(\mathrm{dd}, 1 \mathrm{H}, \mathrm{H}-6 \mathrm{a}, J=12.0$ and $4.8 \mathrm{~Hz}), 4.23$ (dd, $1 \mathrm{H}, \mathrm{H}-6 \mathrm{~b}, J=12.0$ and $2.0 \mathrm{~Hz}), 4.10(\mathrm{~s}, 2 \mathrm{H}$, 


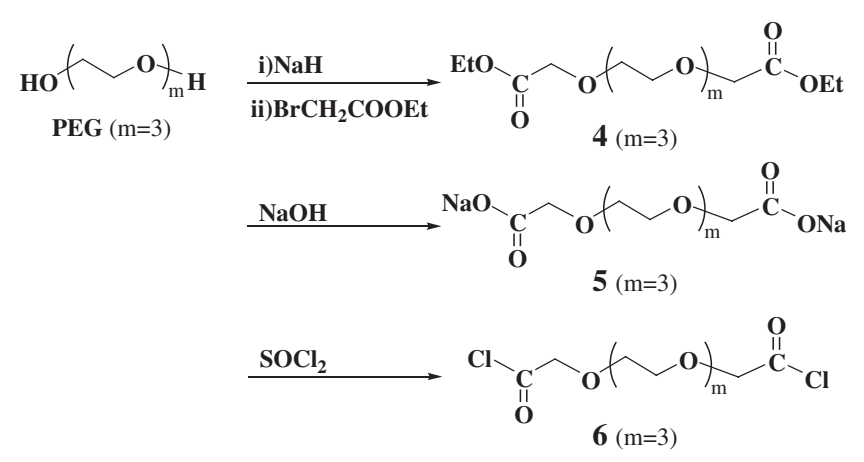

Scheme 2. Synthesis of Coupling Reagent.

- $\mathrm{CH}_{2} \mathrm{OCO}-$ ), 3.79 (t, 1H, H-4, $J=9.6 \mathrm{~Hz}$ ), 3.74 (ddd, 1H, H-5, $J=9.6,4.8$, and $2.0 \mathrm{~Hz}), 3.65\left[\mathrm{t}, 2 \mathrm{H}, J=7.2 \mathrm{~Hz}, \mathrm{CH}_{2} \mathrm{OH}\right.$ (termini of PCL)], 3.50 (dd, 1H, H-2, 3.6 and $9.6 \mathrm{~Hz}), 3.41$ $(\mathrm{t}, 1 \mathrm{H}, \mathrm{H}-3, J=9.6 \mathrm{~Hz}), 3.39\left(\mathrm{~s}, 3 \mathrm{H}, \mathrm{OCH}_{3}\right), 2.41[2 \times \mathrm{brs}$, -OH (PCL terminal and C-4)], $2.11\left(-\mathrm{COCH}_{2}-\right), 1.64$ and 1.38 (- $\mathrm{COCH}_{2} \mathrm{CH}_{2} \mathrm{CH}_{2}-$ ). The obtained protected sugar-head PCL was subsequently deprotected as follows. In a flask, the protected sugar-head PCL $3.0 \mathrm{~g}(\mathrm{n}=45,607 \mathrm{~mol})$ and $10 \% \mathrm{Pd}-$ C $450 \mathrm{mg}$ were dissolved in $30 \mathrm{~mL}$ of THF. The flask was set in an autoclave and hydrogenation proceed at $60^{\circ} \mathrm{C}$ for $3 \mathrm{~d}$ under $\mathrm{H}_{2}$ pressure of $0.93 \mathrm{MPa}$. The filtrate was evaporated to afford the expected sugar-head PCL in an excellent yield $(99 \%)$.

\section{Synthesis of Cross-linking Agent ( $\alpha, \omega$-dicarboxylic Acid} Chloride of PEG) $)^{20,21}$

$\alpha, \omega-\left(\mathrm{OCH}_{2} \mathrm{COOC}_{2} \mathrm{H}_{5}\right)_{2}$ Type of PEG (4). According to Scheme 2, under nitrogen atmosphere, sodium hydride (19.8 g, $820 \mathrm{mmol})$ and THF $(130 \mathrm{~mL})$ were placed in a three-necked flask. Then, from a dropping funnel, PEG $(\mathrm{m}=3,47.6 \mathrm{~mL}$, $320 \mathrm{mmol})$ in THF $(130 \mathrm{~mL})$ was added to the flask over $1 \mathrm{~h}$, and stirred magnetically for another $3 \mathrm{~h}$ at room temperature until the evolution of hydrogen gas ceased. The mixture was cooled again on the ice bath, and ethyl bromoacetate $(89.5 \mathrm{~mL}$, $820 \mathrm{mmol}$ ) to PEG in THF was added through another dropping funnel over $1 \mathrm{~h}$. The mixture was left for $3 \mathrm{~d}$ at room temperature. The mixture was concentrated under the reduced pressure and viscous products were extracted using ethyl acetate. The extract was washed using $\mathrm{NaCl}$ aq. three times and finally with distilled water. It was dried on $\mathrm{MgSO}_{4}$ and subsequently concentrated under reduced pressure and dried up in vacuo. $\left.{ }^{1} \mathrm{H} \mathrm{NMR} \mathrm{(200} \mathrm{MHz}, \mathrm{CDCl}_{3}, \delta, \mathrm{ppm}\right): 4.20$ (q, $\left.2 \times 2 \mathrm{H}, \mathrm{COOCH}_{2} \mathrm{CH}_{3}\right), 4.17\left(\mathrm{~s}, 2 \times 2 \mathrm{H}, \mathrm{CH}_{2} \mathrm{COOCH}_{2} \mathrm{CH}_{3}\right)$, 3.70 (br, $\left.2 \times 4 \mathrm{H},-\mathrm{OCH}_{2} \mathrm{CH}_{2} \mathrm{OCH}_{2} \mathrm{CO}-\right), 3.68$ (s, $4 \mathrm{H},-\mathrm{OCH}_{2}-$ $\left.\mathrm{CH}_{2} \mathrm{O}-\right), 1.28$ (t, $\left.2 \times 3 \mathrm{H}, \mathrm{COOCH}_{2} \mathrm{CH}_{3}\right)$.

$\alpha, \omega-\left(\mathrm{OCH}_{2} \mathrm{COONa}\right)_{2}$ Type of PEG (5). First, the PEG derivative $(4, \mathrm{~m}=3$ ) was added to $7 \mathrm{~mL}$ of aqueous sodium hydroxide $(2.8 \mathrm{M})$ and stirred at $60^{\circ} \mathrm{C}$ for $1 \mathrm{~h}$. After cooling to room temperature, the mixture was washed three times with $50 \mathrm{~mL}$ of methylene chloride. The aqueous layer was freezedried, giving $\mathrm{PEG}$ with $-\mathrm{OCH}_{2} \mathrm{COONa}$ end group, 5 (92\% yield). $\boldsymbol{\alpha}, \boldsymbol{\omega}$-( $\left(\mathrm{OCH}_{2} \mathrm{COCl}\right)_{2}$ Type of PEG (6)..$^{20,21}$ Under nitrogen atmosphere, the PEG derivative $(\mathbf{5}, \mathrm{m}=3,2.1 \mathrm{~g}, 0.05 \mathrm{mmol})$, DMF $(0.5 \mathrm{~mL})$, and toluene $(10 \mathrm{~mL})$ were placed in a threenecked flask and cooled to $0^{\circ} \mathrm{C}$. Thionyl chloride $(1.0 \mathrm{~mL}$, $13.5 \mathrm{mmol}$ ) was added dropwise to the flask, stirring vigorously for $30 \mathrm{~min}$ at $0{ }^{\circ} \mathrm{C}$. Then the mixture was stirred at room temperature for about $18 \mathrm{~h}$ until the gas evolution ceased, and then concentrated in vacuo. Methylene chloride was added to the residue and stirred for $30 \mathrm{~min}$. The precipitate $(\mathrm{NaCl})$ was removed on a glass filter. Through repeated filtration, $\alpha, \omega$ $\left(\mathrm{OCH}_{2} \mathrm{COCl}\right)_{2}$ type of PEG (6) free from $\mathrm{NaCl}$ was obtained $\left(51 \%\right.$ yield). ${ }^{1} \mathrm{H} \mathrm{NMR}\left(200 \mathrm{MHz}, \mathrm{CDCl}_{3}, 25^{\circ} \mathrm{C}, \delta, \mathrm{ppm}\right.$, TMS): $4.51\left(\mathrm{~s}, 2 \times 2 \mathrm{H},-\mathrm{OCH}_{2} \mathrm{COCl}\right), 3.68(\mathrm{~s}, 2 \times 4 \mathrm{H}$, $-\mathrm{OCH}_{2} \mathrm{CH}_{2} \mathrm{OCH}_{2} \mathrm{CO}-$ ), 3.64 (br, $4 \mathrm{H},-\mathrm{OCH}_{2} \mathrm{CH}_{2} \mathrm{O}-$ ).

\section{Synthesis of Triblock Copolymer}

Under a nitrogen atmosphere, the sugar-headed PCL $(n=$ $25,2.5 \mathrm{~g}, 0.94 \mathrm{mmol})$ was placed in a three-neck flask $(30 \mathrm{~mL})$. Dry methylene chloride $(5 \mathrm{~mL})$ and then pyridine $(0.2 \mathrm{~mL}$, $2.6 \mathrm{mmol})$ were added. Through another dropping funnel, the dicarboxylic chloride PEO derivative $(6, \mathrm{~m}=3,0.47 \mathrm{mmol})$ solution in methylene chloride $(5 \mathrm{~mL})$ was added and stirred vigorously for $8 \mathrm{~h}$ at $40^{\circ} \mathrm{C}$. The mixture was dried in vacuo to remove solvents. Triblock copolymer with Sugar-PCL-PEOPCL-Sugar sequence was purified by reprecipitation from chloroform solution into diethyl ether.

Preparation of the Gel Network. The sugar-headed PCL $(1.0 \mathrm{~g}, 0.20 \mathrm{mmol})$ was placed in a three-necked flask. Under $\mathrm{N}_{2}$, PEG derivative $6(\mathrm{~m}=3,1.2 \mathrm{~mL}, 0.10 \mathrm{mmol})$ and toluene $10 \mathrm{~mL}$ and pyridine $0.04 \mathrm{~mL}(0.5 \mu \mathrm{mol})$ were added and refluxed for $24 \mathrm{~h}$. After the reaction, the gel material was washed repeatedly with diethyl ether, and obtained in $96 \%$ yield.

Biodegradation Test. Using a BOD tester (Model 200F; Taitec Co., Koshigaya-shi, Japan) fundamentally according to ISO standard guidelines (ISO 14851), BOD was determined by oxygen consumption at $25^{\circ} \mathrm{C}$. The BOD-based biodegradability was estimated by the percentage of the consumed amount of oxygen, correlated for a blank test to the theoretical amount of oxygen required for complete oxidation of the sample. All BOD values are the means of four samples. Activated sludge was obtained from a sewage plant in Naka-ku, Nagoya. The supernatants $(15 \mathrm{~mL})$ were added to the incubation media $(150 \mathrm{~mL})$, containing the followings $(\mathrm{mg} / \mathrm{L}): \mathrm{K}_{2} \mathrm{HPO}_{4}, 217$; $\mathrm{KH}_{2} \mathrm{PO}_{4}, \quad 85 ; \quad \mathrm{Na}_{2} \mathrm{HPO}_{4}, \quad 447 ; \mathrm{NH}_{4} \mathrm{Cl}, \quad 5 ; \mathrm{CaCl}_{2}, \quad 27$; $\mathrm{MgSO}_{4} \cdot 7 \mathrm{H}_{2} \mathrm{O}, 23$; and $\mathrm{FeCl}_{3} \cdot 6 \mathrm{H}_{2} \mathrm{O}, 0.25$. The sample was $10 \mathrm{mg} / \mathrm{L}$. Furthermore, $\mathrm{NaOH}$ aq. $(11 \mathrm{~mol} / \mathrm{L})$ displayed a relation to $\mathrm{CO}_{2}$ absorption.

Measurements. Nuclear magnetic resonance (NMR) spectra were measured in $\mathrm{CDCl}_{3}$ at $27^{\circ} \mathrm{C}$, containing tetramethylsilane (TMS) as the internal reference, on a spectrometer $(200 \mathrm{MHz}$ for Proton, DPX-Advance-200; Bruker) or a spectrometer (400 MHz for proton, UNITY PLUS-400; Varian). Numberaveraged molecular weights $\left(M_{\mathrm{n}}\right)$ and polydispersity index $\left(M_{\mathrm{w}} / M_{\mathrm{n}}\right)$ of the polymers were estimated through sizeexclusion chromatography (SEC), calibrated with polystyrene 
Table I. Living ROP of $\varepsilon-\mathrm{CL}$ in toluene at $60^{\circ} \mathrm{C}^{\mathrm{a}}$

\begin{tabular}{|c|c|c|c|c|c|c|c|c|c|}
\hline \multirow{2}{*}{\multicolumn{2}{|c|}{ Run $\left[\mathrm{M}_{0}\right] /\left[I_{0}\right.$}} & \multicolumn{2}{|c|}{ Catalyst (mol\%) } & \multirow{2}{*}{$\begin{array}{c}\text { Time } \\
\mathrm{h}\end{array}$} & \multirow{2}{*}{$\begin{array}{l}\left.\text { Yield }{ }^{b}\right) \\
\text { (wt \%) }\end{array}$} & \multicolumn{2}{|c|}{$M_{\mathrm{n}} \times 10^{-3}$} & \multirow{2}{*}{$D^{d} P^{d}$} & \multirow{2}{*}{$M_{\mathrm{w}} / M_{\mathrm{n}}{ }^{\mathrm{c}}$} \\
\hline & & $\mathrm{Sn}(\mathrm{Oct})$ & $\mathrm{c}(\mathrm{OTf})_{3}$ & & & $\overline{(\mathrm{SEC})^{\mathrm{c})}}$ & $(\mathrm{NMR})^{\mathrm{d})}$ & & \\
\hline 1 & 20 & 2.0 & & 96 & 75 & 4.5 & 3.2 & 25 & 1.25 \\
\hline 2 & 40 & 2.0 & & 120 & 99 & 11.4 & 5.5 & 45 & 1.45 \\
\hline 3 & 40 & & 1.0 & 120 & 96 & 9.9 & 4.7 & 38 & 1.48 \\
\hline 4 & 60 & 2.0 & & 144 & 99 & 16.5 & 7.6 & 63 & 1.41 \\
\hline $5^{e)}$ & 20 & 2.0 & & 96 & 99 & 10.3 & 4.0 & 32 & 1.81 \\
\hline
\end{tabular}

a) $[\mathrm{M}]_{0}=5.7 \mathrm{~mol} / \mathrm{L}$. b) $A$-hexane-insoluble fraction. ${ }^{\text {c) }}$ Determined by SEC measurement in chloroform, calibrated by poly(styrene) standards.

d) Determined by ${ }^{1} \mathrm{H}$ NMR based on $\mathrm{OCH}_{3}$ protons in the initiator-moiety.

e) At $120^{\circ} \mathrm{C}$.

standards on GPC-system (DP-8020; Tosoh Corp.) with an RI detector (RI-8020; Tosoh Corp.) and Tosoh G2000-, G3000-, G4000-, and G5000-HXL columns in series (eluent, chloroform; flow rate, $1.0 \mathrm{~mL} / \mathrm{min}$; temperature, $40^{\circ} \mathrm{C}$ ).

\section{RESULTS AND DISCUSSION}

\section{Synthesis of Sugar-head PCL}

Sugar-headed PCL was synthesized according to Scheme 1, expecting that ring-opening polymerization occurred in a living manner. In this case, a sugar derivative, methyl 2,3-Odibenzyl- $\alpha$-D-glucopyranoside (3), was used as an initiator. This initiator possesses two kinds of hydroxyl group, $-\mathrm{CH}_{2} \mathrm{OH}$ (C-6) and $>\mathrm{CHOH}(\mathrm{C}-4)$, which show different nucleophilicity for the initiation reaction in ROP of $\varepsilon$-CL. Therefore, it was necessary to survey conditions in which the initiation reaction from the primary hydroxyl group occurred chemoselectively. Table I represents results of ROP of $\varepsilon$-CL in toluene. All polymers listed in the Table I were confirmed to possess the sugar structure at the $\alpha$-terminal of a PCL chain. As shown from ${ }^{1} \mathrm{H}$ NMR (Figure 1), it was suggested that ROP of $\varepsilon$-CL can be attacked chemoselectively by the primary hydroxyl group at C-6 carbon as the initiator (3). The NMR signals at 3.76 and $3.80 \mathrm{ppm}$ assigned to $-\mathrm{CH}_{2} \mathrm{OH}$ moiety at the $\mathrm{C} 6$ position in the initiator shifted completely to 4.40 and $4.23 \mathrm{ppm}$ because of the $-\mathrm{CH}_{2} \mathrm{OCO}$ - unit in the product polymers (Run $1-4)$, although the signal ascribed to $\mathrm{H}-4$ proton $(3.74 \mathrm{ppm}) \mathrm{did}$ not show a remarkable shift $(3.79 \mathrm{ppm})$. On the other hand, a NMR signal at $2.44 \mathrm{ppm}$ ascribed to C-4 hydroxyl group disappeared completely in the copolymer obtained at $120^{\circ} \mathrm{C}$ (run 5). In addition, the polymer obtained from run $5\left(120^{\circ} \mathrm{C}\right)$ showed a rather complicated split pattern for benzyl protons, suggesting the influence of PCL chain initiated from 4hydroxyl group.

Figure 2 represents the dependence of molecular weight $\left(M_{\mathrm{n}}\right)$ on the conversion at $60^{\circ} \mathrm{C}\left([\mathrm{M}]_{0} /[\mathrm{I}]_{0}=20,40\right.$ and 60$)$, demonstrating that $M_{\mathrm{n}}$ increased linearly as a function of conversion. In runs $1-4, M_{\mathrm{n}}$ of the finally achieved polymers was close to that calculated from $[\varepsilon-\mathrm{CL}]_{0} /[\text { Initiator }]_{0}$. These data suggest that the ring-opening polymerization of $\varepsilon$-CL using glucopyranoside derivative (3) as the initiator and $\mathrm{Sc}(\mathrm{OTf})_{3}$ as well as $\mathrm{Sn}(\mathrm{Oct})_{2}$ catalyst proceeded in a living manner.
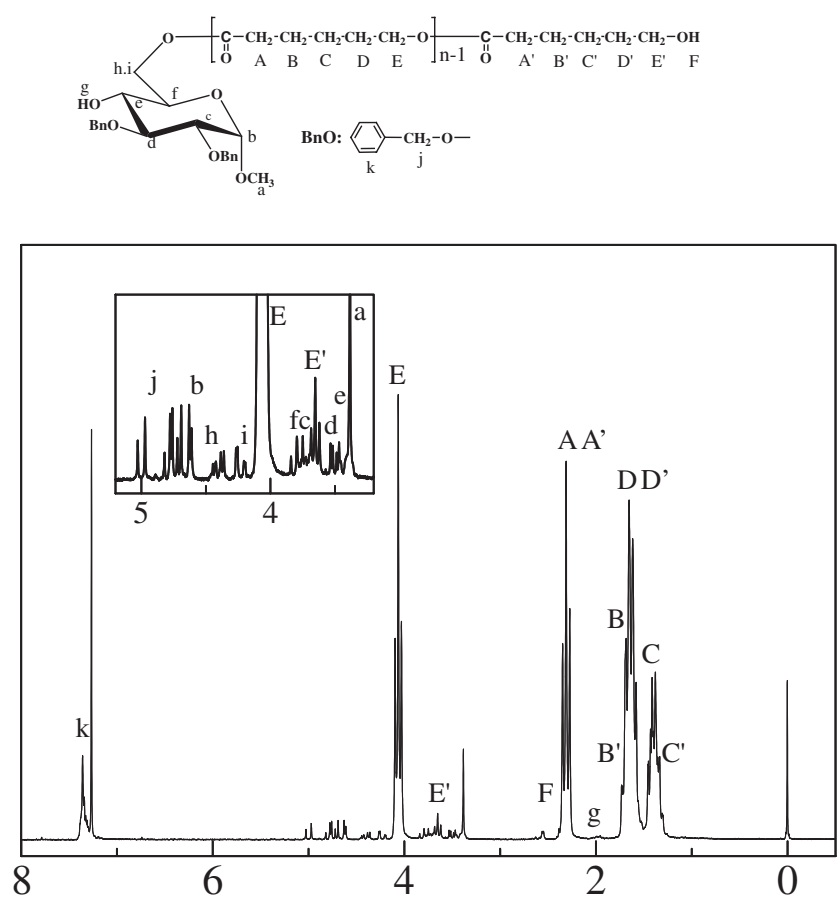

Figure 1. ${ }^{1} \mathrm{H}$ NMR spectra of methyl 2,3-di-O-benzyl-6-O-poly ( $\varepsilon$-caprolactone)- $\alpha$-D-glucopyranoside in $\mathrm{CDCl}_{3}$.

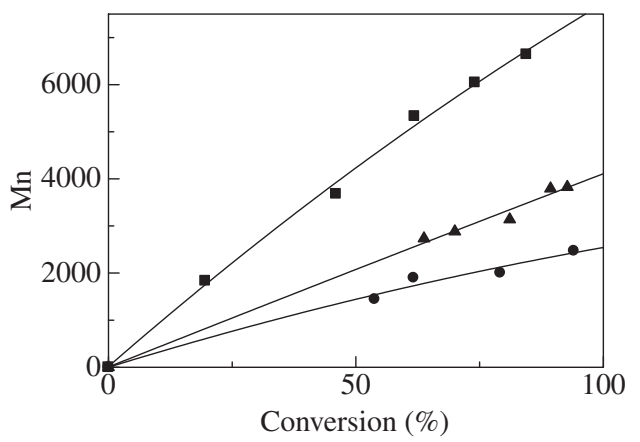

Figure 2. Molecular weight (from SEC) of sugar-PCL as a function of time with variation of $[\mathrm{M}]_{0} /[\mathrm{I}]_{0}$ ratio, $[\mathrm{M}]_{0} /[\mathrm{I}]_{0}=20(\boldsymbol{O}), 40(\boldsymbol{\Delta})$, and 60(ם).

Protection by the benzyl groups for the hydroxyl groups at the C-2 and C-3 carbons was necessary for ROP of $\varepsilon$-CL. In the case of methyl $\alpha$-D-glucopyranoside as the initiator, $\mathrm{Sn}(\mathrm{Oct})_{2}$ did not work as the catalyst under identical conditions. Apparently, $\mathrm{Sn}(\mathrm{Oct})_{2}$ coordinated with hydroxyl groups at the C-2 and C-3 carbons, which deactivated the catalyst.

The obtained protected sugar-head PCL $(n=25$ and 45) was subsequently hydrogenated by $\mathrm{Pd}-\mathrm{C}$ at $60^{\circ} \mathrm{C}$ for $3 \mathrm{~d}$ to give the expected sugar-head PCL in an excellent yield $(99 \%)$.

\section{Synthesis of Triblock Copolymer}

Investigation of gels is difficult because of their insolubility in any solvent. Protected sugar-head PCL $(\mathrm{n}=25)$-block$\operatorname{PEG}(\mathrm{m}=3)$-block-protected sugar-head $\operatorname{PCL}(\mathrm{n}=25)$ was 

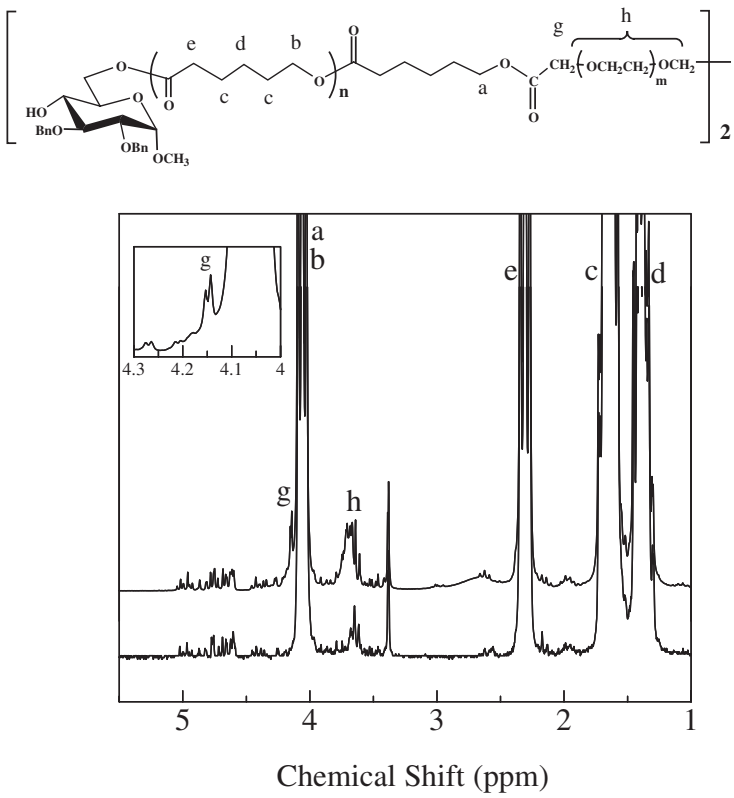

Figure 3. ${ }^{1} \mathrm{H}$ NMR spectra of protected sugar-head $\mathrm{PCL}(\mathrm{n}=25)$-block$\operatorname{PEG}(m=3)$-block-protected sugar-head $\operatorname{PCL}(n=25)$ (top); starting protected sugar-PCL (bottom).
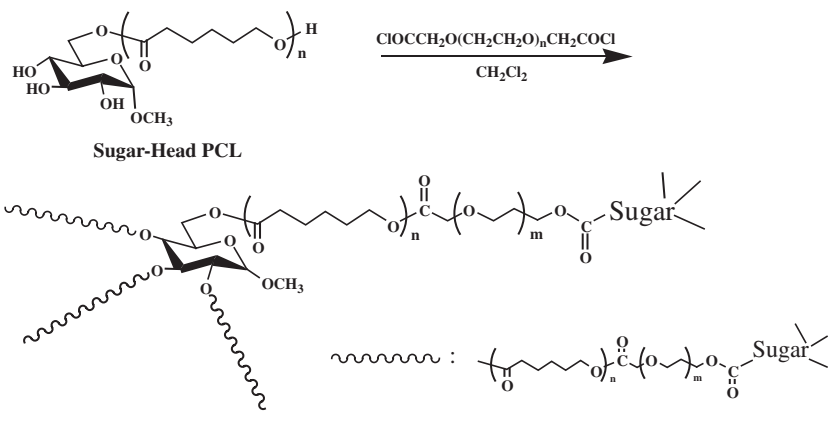

Scheme 3. Synthesis of amphiphilic biodegradable gel network composed of sugar head-PCL and PEG.

prepared by the coupling reaction of the two protected sugarhead PCLs ( $\mathrm{n}=25$, run 1 in Table I), in which the PCL chain length was controlled using the ring-opening polymerization technique $\left(M_{\mathrm{n}}=4.5 \times 10^{3}, M_{\mathrm{w}} / M_{\mathrm{n}}=1.25\right.$ from SEC), with a $\alpha, \omega$-di(acid chloride) type of PEG $(6, \mathrm{~m}=3)$. Using dichloromethane as the reaction solvent, the temperature was $40^{\circ} \mathrm{C}$. Gelation did not occur because the secondary alcohol in the glycoside did not react with the coupling agent. Signals assigned to the terminal $-\mathrm{CH}_{2} \mathrm{OH}$ groups $(2.41 \mathrm{ppm})$ in the sugar-headed PCL as well as a peak at $4.50 \mathrm{ppm}\left(\mathrm{OCH}_{2} \mathrm{COCl}\right)$ disappeared in their ${ }^{1} \mathrm{H}$ NMR spectrum, suggesting that the expected coupling occurred. Figure 3 shows a ${ }^{1} \mathrm{H}$ NMR spectrum of the coupling polymer. The block copolymers were pale-brown soft solids. The molecular weight from SEC measurement of the triblock copolymer obtained in good yield $\left(M_{\mathrm{n}}=10.4 \times 10^{3}, M_{\mathrm{w}} / M_{\mathrm{n}}=1.6_{1}\right)$ did not show discrepancy to the calculated $M_{\mathrm{n}}\left(M_{\mathrm{n}}=7.0 \times 10^{3}\right)$ for protected Sugarhead PCL $(\mathrm{n}=25)$-block-PEG $(\mathrm{m}=3)$-block-protected sugar-

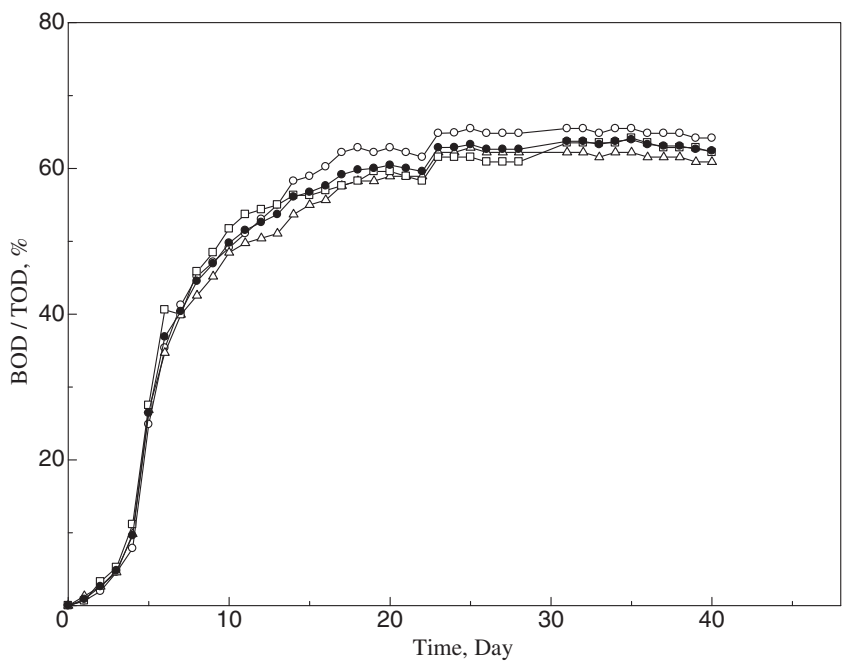

Figure 4. The biodegradation test of the gel $\left(n=25, m=3, p H 7.4,25^{\circ} \mathrm{C}\right)$.

head $\operatorname{PCL}(\mathrm{n}=25)$ and the remarkable broadening of the $M_{\mathrm{w}} / M_{\mathrm{n}}$ was not observed either, compared with that $\left(M_{\mathrm{w}} / M_{\mathrm{n}}=1.2_{5}\right)$ of the parent protected sugar-head PCL. Consequently, it is revealed that the expected Sugar-PCLPEG-PCL-Sugar triblock copolymer can be prepared as a building block for the intended gel.

Preparation of the Gel Network. Preparation of the gel was achieved by reflux in toluene for $24 \mathrm{~h}(\mathrm{n}=25, \mathrm{~m}=3$; $99 \%$ yield) as shown in Scheme 3. The obtained gel material was not soluble in organic solvents and aqueous media but swollen in both the organic and aqueous solvents. The property in the equilibrium swollen state was evaluated by $W_{\mathrm{s}} / W_{0}$ value, in which $W_{\mathrm{s}}$ and $W_{0}$ are weights at swollen and dry state, respectively. The $W_{\mathrm{s}} / W_{0}$ values for several solvents are as follows: 2 (in water), 3 (in dichloromethane), 4 (in toluene), 3 (in ethanol). The results indicated that the PEG chain length $(\mathrm{m}=3)$ is short for preparation of the corresponding hydrogel of higer $W_{\mathrm{s}} / W_{0}$ value. The relationship of swelling behavior and the structure of the gel (PCL/PEO balance, $n / m$ ) will be discussed in a forthcoming paper.

Biodegradability of the Gel. Biodegradation of the gel $(\mathrm{n}=25, \mathrm{~m}=3)$ in activated sludge $\left(\mathrm{pH} 7.4,25^{\circ} \mathrm{C}\right)$ was monitored using BOD. The degradation percentages were calculated from the BOD values and theoretical oxygen demand (TOD) values (Figure 4). The BOD-based biodegradability is defined in the experimental section. All the BOD values showed good reproducibility. In the BOD measurement, the gel was degraded by $c a$. $60 \%$ of BOD/TOD within $20 \mathrm{~d}$. Remarkable degradation of the gel was ascribed to the PCL and sugar segment. The dependence of biodegradability of the gels in the variety of their structures will be also described in detail in a later paper.

Received: October 16, 2007

Accepted: November 21, 2007

Published: January 10, 2008 


\section{REFERENCES}

1. D. Jovanović, M. Nikolić, and J. Djonlagić, J. Serb. Chem. Soc., 69, 1013 (2004).

2. J. Rieger, F. Stoffelbach, D. Cui, A. Imberty, E. Lameignere, J.-L. Putaux, R. Jerome, C. Jerome, and R. Auzely-Velty, Biomacromolecules, 8, 2717 (2007).

3. C. He, J. Sun, T. Zhao, Z. Hong, X. Zhuang, X. Chen, and X. Jing, Biomacromolecules, 7, 252 (2006).

4. M. Ursu, H. Frey, I. Neuner, R. Thomann, and M. Rusu, Rep. Rom. Phys., 56, 445 (2004).

5. Z. Li, M. Gao, M. Yuan, J. Hao, and X. Deng, J. Polym. Sci., Part. A: Polym. Chemistry, 41, 1511 (2003).

6. H. T. Moon, Y. Lee, J. K. Han, and Y. Byun, J. Biomater. Sci., Polym. Ed., 13(7), 817 (2002).

7. Z. Gan, T. F. Jim, M. Li, Z. Yuer, S. Wang, and C. Wu, Macromolecules, 32, 590 (1999).

8. R. Zhang, Polymer, 462443 (2005).

9. L. Chen, Z. Liu, and R. Zhuo, Polymer, 466274 (2005).

10. J. Maia, L. Ferreira, R. Carvalho, M. A. Ramos, and M. H. Gil,
Polymer, 46, 9604 (2005).

11. P. M. L. Gonçalves, S. M. Roberts, and P. W. H. Wan, Tetrahedron, 60, 927 (2004).

12. P. R. Sridhar and S. Chandrasekaran, Org. Lett., 4, 4731 (2002).

13. K. S. Bisht, F. Deng, R. A. Gross, D. L. Kaplan, and G. Swift, J. Am. Chem. Soc., 120, 1363 (1998).

14. H. R. Kricheldorf and A. Stricker, Macromolecules, 33, 696 (2000).

15. K. Inoue, Y. Ono, Y. Kanekiyo, S. Kiyonaka, I. Hamachi, and S. Shinkai, Chem. Lett., 28, 225 (1999).

16. I. Ciucanu and F. Kereck, Carbohydr. Res., 131, 209 (1984).

17. K. Freudenberg, H. Toepffer, and C. C. Andersen, Ber. Dtsch. Chem. Ges., 61, 1750 (1928).

18. M. E. Evans, Carbohydr. Res., 21, 473 (1972).

19. C. C. Joseph, B. Zwanenburg, and G. J. F. Chittenden, Synthetic Commun., 33, 493 (2003).

20. T. Lodi, R. Marchelli, A. Dossena, E. Dradi, and G. Casnati, Tetrahedron, 38, 2055 (1982).

21. P. R. Ashton, B. Horner, O. Kocian, S. Menzer, A. J. P. White, J. F. Stoddat, and D. J. Williams, Synthesis, 8, 930 (1996). 